\title{
Prognostic Factors for Inguinal Lymph Node Involvement and Tumor Recurrence in Squamous Cell Carcinoma of the Penis
}

\section{Factores pronósticos de compromiso ganglionar inguinal y recaída tumoral en carcinoma escamocelular de pene}

\begin{abstract}
J. Gustavo Ramos ${ }^{1}$ Angie Ramírez ${ }^{1}$ Rodolfo Varela ${ }^{1}$ Daniela Robledo ${ }^{1}$ José De la Hoz-Valle ${ }^{1}$ Rafael Vargas ${ }^{1}$ Jorge Forero ${ }^{1}$ Fabián Godoy ${ }^{1}$ Marino Cabrera ${ }^{1}$ Claudia Ochoa ${ }^{1}$ Byron López ${ }^{1}$ Wilfredo Donoso ${ }^{1}$ Sergio Giraldo ${ }^{1}$ Carolina Pinzón ${ }^{1}$ Sara Peralta ${ }^{1}$ Andrés Calderón ${ }^{1}$
\end{abstract}

\footnotetext{
${ }^{1}$ Department of Oncological Urology, Instituto Nacional de Cancerología, Bogotá, Colombia
}

Address for correspondence Jose Gustavo Ramos Ulloa, MD, Bogotá, 111511, Colombia (e-mail: josegustavoramos@gmail.com).

Urol Colomb 2020;29:84-90.

\begin{abstract}
Keywords

- lymphovascular invasion

- penile carcinoma

- tumor recurrence

- degree of tumor differentiation

Introduction Penile carcinoma is an aggressive disease with catastrophic consequences that frequently lead to death. Therefore, further knowledge on the prognostic factors that can help identify patients in need of more aggressive treatments becomes essential.

Objective To identify the prognostic factors for lymph node (LN) involvement and tumor recurrence in patients diagnosed with squamous cell carcinoma of the penis (SCCP).

Methods A retrospective cohort study was conducted. Patients diagnosed and treated for SCCP at Instituto Nacional de Cancerología between 2008 and 2015 were included in the sample. Cases in which no information on recurrence was available for the follow-up were excluded, as well as patients with no initial pathology and those getting penile reconstructions after cancer.

Relevant data was retrieved from the medical records of each patient, and a descriptive analysis was performed. Subsequently, this data was used to apply a logistic regression model to determine the potential clinical and histopathological prognostic factors.

Results A total of 104 patients were included in the present study. The average age of the sample was 59 years, while the follow-up averaged 24 months per patient. Inguinal lymphadenectomy was performed on 61 patients (59\%) during the follow-up. The logistic regression model showed that lymphovascular invasion (odds ratio [OR]: 6.7; 95\% confidence interval [95\%Cl]:1.2-35) and poor tumor differentiation (OR: 17; 95\%Cl:3.2-92) were associated with tumor recurrence. Likewise, the lymphadenectomy procedures showed that lymphovascular invasion was associated with LN involvement (OR: 3.3; 95\%Cl: 1.1-10).

Conclusion Lymphovascular invasion was the strongest prognostic factor observed in our sample, aiding in the prediction of inguinal $L N$ involvement and tumor recurrence in SCCP patients.
\end{abstract}

received

March 10, 2019

accepted after revision July 26, 2019
DOI https://doi.org/

10.1055/s-0039-1697997.

ISSN 0120-789X.

e ISSN 2027-0119.
Copyright (c) 2020, Sociedad Colombiana License terms de Urología. Publicado por Thieme Revinter Publicações Ltda., Rio de Janeiro, Brazil. Todos los derechos reservados. 


\section{Resumen}

\author{
Palabras-clave \\ - invasión linfovascular \\ - cáncer de pene \\ - recurrencia tumoral \\ - grado de \\ diferenciación \\ tumoral
}

\section{Patient Summary}

Introduccion El cáncer de pene es una enfermedad agresiva con consecuencias catastróficas que frecuentemente llevan a la muerte. Por lo tanto, es esencial un mayor conocimiento sobre los factores pronósticos que pueden ayudar a identificar a los pacientes que necesitan tratamientos más agresivos.

Objetivo Identificar los factores pronósticos patológicos de compromiso ganglionar inguinal y recaída tumoral en pacientes con carcinoma escamocelular de pene.

Métodos Se realizó un estudio de cohorte retrospectivo. Se incluyeron en la muestra pacientes diagnosticados y tratados por carcinoma escamocelular de pene (SCCP) en el Instituto Nacional de Cancerología entre 2008 y 2015. Los casos en los que no había información sobre la recurrencia en el seguimiento fueron excluidos, así como los pacientes sin patología inicial y aquellos que reciben reconstrucciones del pene después del cáncer. Se recuperaron los datos relevantes de los registros médicos de cada paciente, y una descripción fue realizada. Posteriormente, estos datos se utilizaron para aplicar un modelo de regresión logística para determinar los posibles factores pronósticos clínicos e histopatológicos.

Resultados Un total de 104 pacientes fueron incluidos en el estudio. La edad promedio de la muestra fue de 59 años, mientras que el seguimiento promedió fue de 24 meses por paciente. La linfadenectomía inguinal se realizó en 61 pacientes (59\%) durante el seguimiento. El modelo de regresión logística mostró que la invasión linfovascular (odds ratio [OR]: 6,7; intervalo de confianza del 95\% [IC 95\%]: 1,2-35) y la pobre diferenciación tumoral (OR: 17; IC 95\%: 3,2-92) se asociaron con recurrencia tumoral. Así mismo, los procedimientos de linfadenectomía mostraron que la invasión linfovascular se asoció con afectación de LN. (OR: 3,3; IC 95\%: 1,1-10).

Conclusión La invasión linfovascular es el factor pronóstico independiente más importante que se asocia de manera independiente con compromiso ganglionar inguinal positivo y recaída tumoral.

Lymphovascular invasion should be the main factor to determine the management and follow-up of SCCP patients.

\section{Introduction}

Squamous cell carcinoma of the penis (SCCP) constitutes a pathology with high morbidity and rapid progression. Its consequences are primarily marked in local, regional and systemic grades of involvement. ${ }^{1-3}$

The epidemiology of the disease presents marked geographical differences apparently related to socioeconomic and cultural factors. ${ }^{4}$ Jewish, circumcised-at-birth males in Israel constitute the population with the lowest incidence of this disease. Developed countries also report a low incidence, with rates of 0.2 for every 100,000 males. ${ }^{5}$ However, the incidence of penile cancer in developing countries is on the rise, ${ }^{6}$ particularly in regions with high levels of poverty and among rural populations (such as in South America, Africa and Asia). In such regions, the disease is considered a public health issue representing up to $20 \%$ of reported malignant neoplasms. ${ }^{7-9}$

In Colombia, the available information on the epidemiology of SCCP is limited. The study by Ramírez and Bermúdez Puppo $^{10}$ reported an incidence of 1.11 cases for every 100,000 males. A significant percentage of the cases reported in the study (62.7\%) were from rural areas. In addition, 71.5\% of the cases were diagnosed in advanced stages of the disease $(\geq \mathrm{T} 2)$, reflecting the delay on the part of the patients to seek medical treatment from 6 months up to ayear from the moment when the symptoms arise. ${ }^{5,11}$

Proper staging is crucial in the treatment and prognosis of patients with SCCP. Two factors must be considered in the staging: the level of local extension of the disease and the state of the lymph nodes (LNs), and the former is considered by the European Association of Urology (EAU) and the United States National Comprehensive Cancer Network (NCCN) as the main survival prognostic factor for this disease. ${ }^{12,13}$

The physical examination still is the main tool in the staging of SCCP. Even though this tool is useful in the detection of superficial inguinal adenopathies, it presents limitations, with a false negative rate of approximately $11 \%$ and $62 \%$ of the cases. ${ }^{14-16}$ Therefore, inguinal lymphadenectomy is by far the most accurate method to detect $\mathrm{LN}$ metastasis and to conduct a proper staging of the disease. In addition, high-risk cases on which early lymphadenectomy has been performed show benefits regarding survival rates. ${ }^{17,18}$ However, one of the main limitations for the widespread performance of this 
procedure is the risk involved and the high morbidity (25$50 \%$, which is worsened by longer operation and hospitalization periods. ${ }^{19-21}$

Given the limitations presented by the physical examination technique, current studies are evaluating other options for the diagnosis, such as ultrasonography, computed tomography (CT) scans, nuclear magnetic resonance (NMR) and positron emission tomography (PET) scans. ${ }^{22-24}$ Fine needle aspiration biopsy, sentinel LN mapping and some prediction nomograms are the currently available techniques. ${ }^{25-27}$

Some authors in related published studies seek to correlate the histological factors with the possible progression of the disease. Such histological factors include lymphovascular invasion, pathologic staging and histological differentiation. ${ }^{14}$ However, there are no such studies available performed in Colombia.

Considering the lack of information related to SCCP in Colombia, more studies are needed to deepen the understanding of the disease and its local impact. Thus, the purpose of the present study is to identify the clinical and pathological prognostic factors for inguinal LN involvement and tumor recurrence in cases of SCCP.

\section{Methods}

A retrospective cohort study was conducted. Patients diagnosed and treated for SCCP at Colombia's Instituto Nacional de Cancerología between 2008 and 2015 were included in the sample. A total of 139 cases were collected, but 35 were excluded under the following criteria: cases in which no information on recurrence was available for the follow-up, patients with no initial pathology, and patients getting penile reconstructions after the cancer treatment. In the remaining 104 cases, the clinical and histopathological aspects of inguinal LN involvement and tumor recurrence were evaluated.

The follow-up protocol contemplates the realization of inguinal radical lymphadenectomy in the presence of clinical nodal disease. In patients without clinical nodal disease, sentinel LN biopsy is performed; if the biopsy is positive, the patients are submitted to inguinal lymphadenectomy. If the result is negative, they continue with the clinical surveillance without surgical intervention.

The data was inserted into an Excel (Microsoft Corp., Redmond, WA, US) spreadsheet for a subsequent descriptive analysis, stating frequencies, central tendency and dispersion measurements using both discrete and continuous variables.

For the analytical study, the clinical and histopathological aspects evaluated were: pathological staging, lymphovascular invasion, degree of tumor differentiation, as well as nodal state. A subsequent bivariate analysis was conducted to enable the construction of a multivariate logistic regression model using statistically significant variables to determine the prognostic factors associated with the need to perform inguinal lymphadenectomy, or for the tumor recurrence subsequent to lymphadenectomy.

The presence of distant metastasis disease or pelvic LN after inguinal lymphadenectomy is considered tumor recurrence.

The statistical software used in the present study was the Stata (StataCorp LLC, College Station, TX, US), version12.0.
Statistical significance was assumed for predictions with values of $p<0.05$.

\section{Results}

The average follow-up was of 24.41 months per patient. Tumor recurrence was observed in 22 (21\%) of the cases. The average patient age was 59 years. Most patients sought medical help given the presence of lesions in the physical examination. Most patients presented this lesion in the glans ( $\mathbf{- T a b l e ~} \mathbf{1}$ ).

Bogota was the region of the country where most cases originated, followed by the Cundiboyacense and the Llanos regions (-Table $\mathbf{1}$ ). Clinically, most lesions were deemed to be in stage T2. A total of $71(68 \%)$ of the cases were treated through surgery (penectomy).

Among the gathered medical records, only 65 (62.5\%) indicated whether the patient presented phimosis or not. Out of these 65 cases, 43 (66.1\%) indicated phimosis while the remaining 22 (33.8\%) indicated that there was no phimosis. When reported pathologies were evaluated for the cases studied, it was determined that most patients were in pathological stage (p) T2, with stage pT1 being second in importance (specifically pT1a) (-Fig. 1).

Table 1 Demographic and clinical characteristics of the patients

\begin{tabular}{|c|c|}
\hline Variable & Frequency (\%) \\
\hline Age, years (average) & $59(27-84)$ \\
\hline \multicolumn{2}{|l|}{ Geographical origin } \\
\hline Bogotá & $57(54.8 \%)$ \\
\hline Llanos Orientales & $17(16.3 \%)$ \\
\hline Tolima - Huila & $11(10.5 \%)$ \\
\hline Eje Cafetero & $7(6.7 \%)$ \\
\hline Valle del Cauca y Nariño & $5(4.8 \%)$ \\
\hline Santander y Norte de Santander & $4(3.8 \%)$ \\
\hline Caribe/San Andrés & $3(2.8 \%)$ \\
\hline \multicolumn{2}{|l|}{ Involved region of the penis } \\
\hline Glans & $41(42 \%)$ \\
\hline Balano-preputial sulcus & $21(16.5 \%)$ \\
\hline Prepuce & $15(14.3 \%)$ \\
\hline Penile body & $9(5.7 \%)$ \\
\hline $\begin{array}{l}\text { Glans + prepuce + balano-preputial } \\
\text { sulcus }\end{array}$ & $10(10.7 \%)$ \\
\hline $\begin{array}{l}\text { Glans + prepuce }+ \text { balano-preputial } \\
\text { sulcus }+ \text { penile body }\end{array}$ & $8(7.1 \%)$ \\
\hline \multicolumn{2}{|l|}{ Clinical T stage } \\
\hline Tis & $2(1.9 \%)$ \\
\hline $\mathrm{Ta}$ & 27 (25.9\%) \\
\hline T1 & $8(7.6 \%)$ \\
\hline $\mathrm{T} 2$ & $58(55.7 \%)$ \\
\hline T3 & $7(6.7 \%)$ \\
\hline T4 & $2(1.9 \%)$ \\
\hline
\end{tabular}




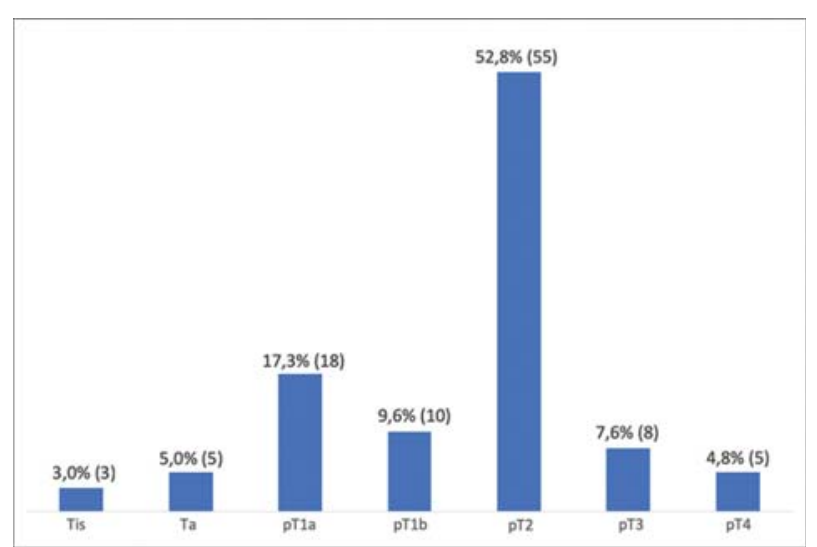

Fig. 1 Distribution of cases by pathologic staging.

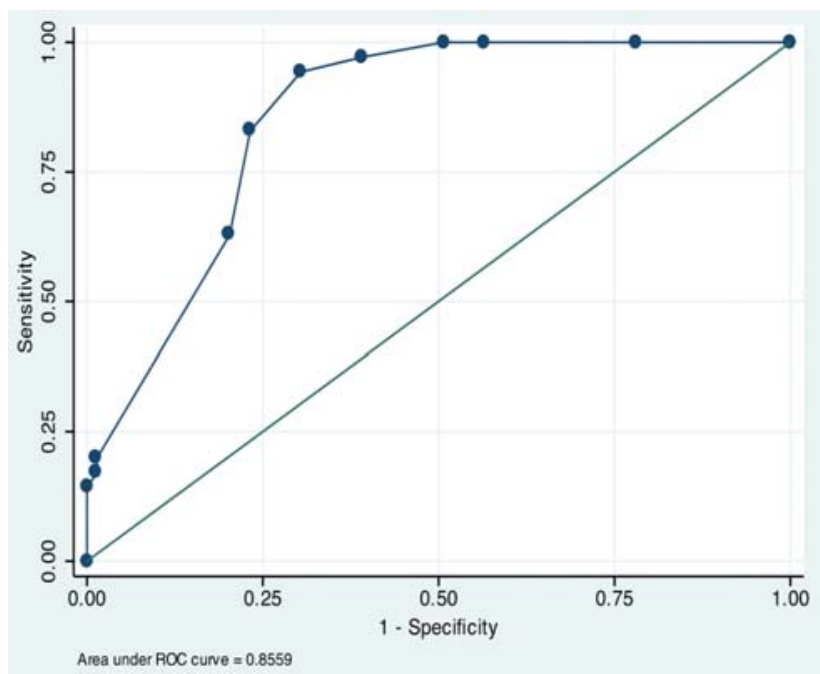

Fig. 2 Statistical Analysis - Inguinal Involvement. Area under the curve ROC 0.85 .

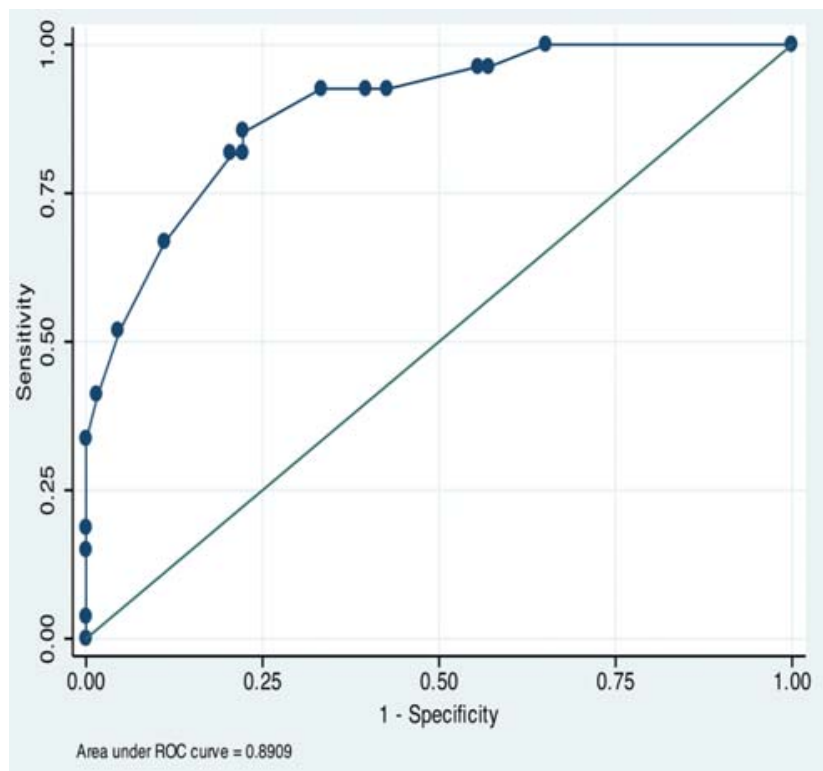

Fig. 3 Statistical Analysis - Tumor Recurrence. Area under the curve ROC 0.89 .
During the follow-up, 61 (59\%) out of 104 patients were submitted to inguinal lymphadenectomies, with 34 (56.3\%) of the cases testing positive for $\mathrm{LN}$ involvement. Out of the lymphadenectomies performed, 55 (90\%) were unilateral and $6(10 \%)$ were bilateral.

The medical literature was consulted to determine which pathologic and clinical variables should be evaluated regarding their correlation with tumor recurrence and inguinal $\mathrm{LN}$ involvement during the follow-up.

A single-variable analysis was conducted to determine the correlation between each one of the variables and the outcomes sought to be predicted (-Tables $\mathbf{2}$ and $\mathbf{3}$ ). Later, the statistically significant variables were used to run a logistic regression model (the independence between the variables was previously confirmed).

The single-variable analysis showed that factors such as pathologic stage, lymphovascular invasion and degree of histologic differentiation of the tumor were associated with inguinal $\mathrm{LN}$ involvement and tumor recurrence. The nodal state was also a factor associated with such outcomes. However, the logistic regression model demonstrated that lymphovascular invasion (odds ratio [OR]: 6.7) and the degree of tumor differentiation (OR: 17) were the only factors associated with tumor recurrence. Moreover, lymphovascular invasion was shown to be associated with inguinal $\mathrm{LN}$ involvement after the performance of the inguinal lymphadenectomy (OR: 3.3).

It is worth mentioning that from the analyzed subpopulation, 19 (18\%) of the cases had pelvic lymphadenectomy performed during the follow-up. Out of the population that presented tumor recurrence, close to $20(90 \%)$ underwent chemotherapy, with cisplatin plus 5 -fluorouracile being the most used treatment scheme. Only 16 (73\%) patients underwent radiotherapy as part of their treatment during the follow-up.

\section{Discussion}

Penile cancer is a disease that has a higher incidence in Colombia compared with that of developed countries. In the present study, most cases originated in the Bogota and Cundiboyacense regions, with an important number of cases originating in other distant regions as well.

It is known that this pathology has a rapid progression rate, and that currently there are not enough imaging tools available to accurately determine the level of compromise caused by the disease. Such rapid progression enables the disease to reach the lymphatic system by penetrating the Buck fascia, as well as by invading the corpus cavernosum just after involving the tunica albuginea. ${ }^{28}$ In the nodal level, it initially invades superficial LNs in the groin, followed by the deep inguinal LNs and, subsequently, the pelvis LNs. Such a progression is characteristic of a disease that has reached the metastatic stage. ${ }^{5,10}$

Therefore, inguinal lymphadenectomy continues to be the best technique to detect $\mathrm{LN}$ involvement, enabling the proper staging of the disease, which has a positive impact in the survival rate of patients in a 5 -year period. ${ }^{22,23,29}$ Such 
Table 2 Single- and multiple-variable analysis of positive inguinal involvement in lymphadenectomy

\begin{tabular}{|l|l|l|l|l|l|l|}
\hline & \multicolumn{3}{l|}{ Single-variable analysis } & \multicolumn{3}{l|}{ Multiple-variable analysis } \\
\hline Variable & OR & $95 \% \mathrm{Cl}$ & $\mathbf{p}$-value & OR & $\mathbf{9 5 \% C l}$ & $p$-value \\
\hline$\geq \mathrm{pT2}$ & 1.7 & $0.6-4.6$ & 0.06 & 1.1 & $0.3-3.6$ & 0.8 \\
\hline Lymphovascular invasion & 7 & $2.4-23$ & $\mathbf{0 . 0 0 1}$ & $\mathbf{3 . 3}$ & $\mathbf{1 . 1 - 1 0}$ & $\mathbf{0 . 0 4}$ \\
\hline Inguinal lymphadenectomy & 52 & $7.6-258$ & 0.001 & 31 & $3.9-248$ & 0.001 \\
\hline Positive lymph nodes in LP & 17 & $1.9-70$ & 0.005 & 6 & $0.6-55$ & 0.113 \\
\hline Histological degree/differentiation & 3 & $0.8-10$ & 0.03 & 2 & $3.4-80$ & 0.9 \\
\hline
\end{tabular}

Abbreviations: $95 \% \mathrm{Cl}, 95 \%$ confidence interval; LP, pelvic lymphadenectomy; OR, odds ratio.

Table 3 Single- and multiple-variable analysis for tumor recurrence

\begin{tabular}{|l|l|l|l|l|l|l|}
\hline & \multicolumn{3}{|l|}{ Single-variable analysis } & \multicolumn{3}{l|}{ Multiple-variable analysis } \\
\hline Variable & OR & $95 \% \mathrm{Cl}$ & p-value & OR & $\mathbf{9 5 \% C I}$ & $p$-value \\
\hline$\geq \mathrm{pT2}$ & 3.6 & $1.1-13.4$ & 0.0053 & 1.2 & $0.1-5$ & 0.9 \\
\hline Lymphovascular invasion & 12.7 & $3.3-69$ & $\mathbf{0 . 0 0 1}$ & $\mathbf{6 . 7}$ & $\mathbf{1 . 2 - 3 5}$ & $\mathbf{0 . 0 2}$ \\
\hline Lymph nodes observed in the test & 4.5 & $1.5-14$ & 0.002 & 1.6 & $0.2-8.9$ & 0.58 \\
\hline Pelvic lymphadenectomy & 3.5 & $1-11.5$ & 0.01 & 5.4 & $1.1-25$ & 0.052 \\
\hline Histological degree/differentiation & 8.4 & $2.2-34$ & $\mathbf{0 . 0 0 1}$ & $\mathbf{1 7}$ & $\mathbf{3 . 2 - 9 2}$ & $\mathbf{0 . 0 0 1}$ \\
\hline cN3 & 4.6 & $1.5-13.7$ & 0.0012 & 4 & $0.9-20$ & 0.059 \\
\hline
\end{tabular}

Abbreviations: $95 \% \mathrm{Cl}, 95 \%$ confidence interval; cN3, plapable fixed inguinal nodal mass or pelvic lymphadenopathy unilateral or bilateral; OR, odds ratio.

results can be achieved especially when the disease is in a nodal stage lower than pN2, without any extra capsular involvement of the nodule and unilateral affectations without any compromise of the pelvic LNs, cases in which a survival rate of $80 \%$ was observed. ${ }^{17,18}$

The study of this topic is of particular relevance when considering that $20 \%$ of the patients clinically staged as negative for cancerous cells present hidden metastases, while $77 \%$ of the patients with high-risk SCCP have negative lymphadenectomies that are negative for LN involvement. Such facts indicate that there is a high rate of patients being over-treated, while the need for a proper and effective staging of the risk of metastasis in this disease is certainly highlighted. ${ }^{17,24,30}$

With the purposes of predicting the risk of LN metastasis, identifying the patients that would benefit from an inguinal lymphadenectomy, as well as identifying those under risk of tumor recurrence, various clinical and histological factors have been determined: tumor staging, growth pattern, level of invasion, thickness of the lesion, degree of the tumor and nucleus, number of mitoses, vascular and lymphatic involvement, among other factors. ${ }^{14,31}$

The physical examination is still the main clinical tool to stage the disease, and it is primarily based on the description of the perceived affectation of adjacent structures such as the urethra, the corpus cavernosum, the scrotum, the prostate and the pubis, as well as the palpation of superficial LNs. In a Canadian study, Beech et $\mathrm{al}^{3}$ found that nodal staging was the factor with the most significance in cancerspecific survival rates.
In 2001, Slaton et al $^{14}$ evaluated a group of 48 patients diagnosed and treated surgically for invasive SCCP. The authors also evaluated several histopathological factors regarding their effectiveness in predicting metastases in inguinal LNs. The study determined through a multivariate analysis that factors such as stages $\geq$ pT2 $(p=0.012)$, vascular invasion $(p=0.005)$, and poorly-differentiated tumor $(p=0.043)$ in more than $50 \%$ of the sample were closely associated with LN involvement. ${ }^{14}$

Another study, conducted by Ficarra et al $^{34}$ with a sample of 175 patients who underwent partial or total penectomies, also tried to determine the prognostic factors for LN involvement. The factors found to be effective in the prediction were: thickness of the tumor $>5 \mathrm{~mm}$, superficial growth pattern of the tumor, high stage of the disease, lymphovascular invasion, corpus cavernosum invasion, urethral invasion and LNs testing positive under physical examination. ${ }^{32-34}$

In the context of the existing literature, the purpose of the present study was to evaluate the likely prognostic factors for inguinal involvement and tumor recurrence in an attempt to obtain a representative sample of the Colombian population. Clinical and histological factors were considered in the study, such as nodal evaluation during the physical examination, pathological stage, lymphovascular invasion, and degree of histological tumor differentiation. The internal correlation was evaluated using variables such as the performance of inguinal and pelvic lymphadenectomies (with the LNs testing positive), as well as tumor recurrence. 
The present study showed (similar to what was concluded by Beech et $\mathrm{al}^{3}$ ) that nodal state and the presence of LNs in the physical examination is associated with inguinal LN involvement and tumor recurrence, with a high statistical significance in the single variable analysis. In line with the findings by Slaton et al ${ }^{14}$ and Ficarra et al, ${ }^{34}$ histopathological factors such as pT2, lymphovascular invasion and degree of histological differentiation of the tumor were shown to be connected to inguinal LN involvement and tumor recurrence, with a high degree of statistical significance in the singlevariable analysis.

In the construction of the logistic regression model, we found that lymphovascular invasion was the one factor that was independently associated with inguinal LN involvement, as well as tumor recurrence, with ORs of 3.3 and 6.7 for each of the mentioned prognostic factors respectively. This result is in line with the findings of other studies, such as the one by Ficarra et al, ${ }^{34}$ in which lymphovascular invasion is the main predictor for LN involvement (OR: 5.3), with the difference that the present study also found tumor recurrence to be connected.

Other factors that have been widely studied in the related literature were also considered in the present study. For instance, the degree of histological differentiation for the tumor was tested, and we found that there was a statistical correlation between this prognostic factor and LN involvement. However, no correlation was found between the mentioned prognostic factor and tumor recurrence. The present study also provided strong foundations, as it showed how inguinal lymphadenectomy results were associated with tumor recurrence.

It is important to mention that the models used for the present study have an area under the curve (AUC) above $80 \%$, indicating their high level of sensitivity and specificity.

\section{Conclusions}

Lymphovascular invasion was the main prognostic factor for tumor recurrence and inguinal LN involvement in the sample of the present study. However, more studies on this topic are needed with increased follow-up, and to further investigate the effectiveness of other prognostic factors that help predict more effectively the development of the disease among cancer patients in Colombia.

This study took into account for its implementation the regulations of Article 11 of Resolution No. 008430 of 1993 (Issued by the Colombian Ministry of Health). Similarly, it considered international regulations (in particular, the Declaration of Helsinki and the ethical guidelines for biomedical research prepared by the Council of International Organizations of Medical Sciences, CIOMS) and the parameters established at the national level by Resolution 8430 of 1993 and Resolution 2378 of 2008 (issued by the Colombian Ministry of Social Protection).

Conflict of Interests

The authors have no conflict of interests to declare.

\section{References}

1 Barocas DA, Chang SS. Penile cancer: clinical presentation, diagnosis, and staging. Urol Clin North Am 2010;37(03):343-352

2 Cataño JGC, Niño JFP, Schlessinger AA. Manejo actual del cáncer de pene en el Hospital Universitario de San Ignacio. Revista Urol Colomb. 2010;19(01):1

3 Beech B, Izawa J, Pautler S, Chin J, Power N. Penile cancer: Perspective from a Canadian tertiary care centre. Can Urol Assoc J 2015;9(9-10):315-319

4 Hernandez BY, Barnholtz-Sloan J, German RR, et al. Burden of invasive squamous cell carcinoma of the penis in the United States, 1998-2003. Cancer 2008;113(10, Suppl):2883-2891

5 Pow-Sang MR, Ferreira U, Pow-Sang JM, Nardi AC, Destefano V. Epidemiology and natural history of penile cancer. Urology 2010; 76(02, Suppl 1):S2-S6

6 Siegel RL, Miller KD, Jemal A. Cancer statistics, 2015. CA Cancer J Clin 2015;65(01):5-29

7 Favorito LA, Nardi AC, Ronalsa M, Zequi SC, Sampaio FJB, Glina S. Epidemiologic study on penile cancer in Brazil. Int Braz J Urol Off J Braz Soc Urol 2008;34;5:587-591; discussion 591-3

8 Pahwa M, Girotra M, Rautela A, Abrahim R. Penile cancer in India: a clinicoepidemiological study. Gulf J Oncolog 2012;(12):7-10

9 Chalya PL, Rambau PF, Masalu N, Simbila S. Ten-year surgical experiences with penile cancer at a tertiary care hospital in northwestern Tanzania: a retrospective study of 236 patients. World J Surg Oncol 2015;13:71. cited 2016 Jun 8 [Internet]. http:// www.ncbi.nlm.nih.gov/pmc/articles/PMC4341227/

10 Ramírez G, Bermúdez Puppo AJ. Carcinoma de Pene. Urol Colomb22:37-3

11 Narayana AS, Olney LE, Loening SA, Weimar GW, Culp DA. Carcinoma of the penis: analysis of 219 cases. Cancer 1982;49 (10):2185-2191

12 Hakenberg OW, Compérat EM, Minhas S, Necchi A, Protzel C, Watkin N. EAU guidelines on penile cancer: 2014 update. Eur Urol 2015;67(01):142-150

13 Clark PE, Spiess PE, Agarwal N, et al; National Comprehensive Cancer Network. Penile cancer: Clinical Practice Guidelines in Oncology. J Natl Compr Canc Netw 2013;11(05):594-615

14 Slaton JW, Morgenstern N, Levy DA, et al. Tumor stage, vascular invasion and the percentage of poorly differentiated cancer: independent prognosticators for inguinal lymph node metastasis in penile squamous cancer. JUrol 2001;165(04):1138-1142

15 Lam W, Alnajjar HM, La-Touche S, et al. Dynamic sentinel lymph node biopsy in patients with invasive squamous cell carcinoma of the penis: a prospective study of the long-term outcome of 500 inguinal basins assessed at a single institution. Eur Urol 2013;63 (04):657-663

16 Leijte JAP, Kroon BK, Valdés Olmos RA, Nieweg OE, Horenblas S. Reliability and safety of current dynamic sentinel node biopsy for penile carcinoma. Eur Urol 2007;52(01):170-177

17 Marconnet L, Rigaud J, Bouchot O. Long-term followup of penile carcinoma with high risk for lymph node invasion treated with inguinal lymphadenectomy. JUrol 2010;183(06):2227-2232

18 Lont AP, Kroon BK, Gallee MPW, van Tinteren H, Moonen LMF, Horenblas S. Pelvic lymph node dissection for penile carcinoma: extent of inguinal lymph node involvement as an indicator for pelvic lymph node involvement and survival. J Urol 2007;177(03): 947-952, discussion 952

19 Bouchot O, Rigaud J, Maillet F, Hetet JF, Karam G. Morbidity of inguinal lymphadenectomy for invasive penile carcinoma. Eur Urol 2004;45(06):761-765, discussion 765-766

20 Yao K, Tu H, Li Y-H, et al. Modified technique of radical inguinal lymphadenectomy for penile carcinoma: morbidity and outcome. JUrol 2010;184(02):546-552

21 Nelson BA, Cookson MS, Smith JA Jr, Chang SS. Complications of inguinal and pelvic lymphadenectomy for squamous cell carcinoma of the penis: a contemporary series. JUrol 2004;172(02): 494-497 
22 Johnson DE, Lo RK. Management of regional lymph nodes in penile carcinoma. Five-year results following therapeutic groin dissections. Urology 1984;24(04):308-311

23 Fraley EE, Zhang G, Manivel C, Niehans GA. The role of ilioinguinal lymphadenectomy and significance of histological differentiation in treatment of carcinoma of the penis. JUrol 1989;142(06): $1478-1482$

24 Graafland NM, Lam W, Leijte JAP, et al. Prognostic factors for occult inguinal lymph node involvement in penile carcinoma and assessment of the high-risk EAU subgroup: a two-institution analysis of 342 clinically node-negative patients. Eur Urol 2010; 58(05):742-747

25 Kochhar R, Taylor B, Sangar V. Imaging in primary penile cancer: current status and future directions. Eur Radiol 2010;20(01):36-47

26 Cabanas RM. Anatomy and biopsy of sentinel lymph nodes. Urol Clin North Am 1992;19(02):267-276

27 Solsona E, Iborra I, Rubio J, Casanova JL, Ricós JV, Calabuig C. Prospective validation of the association of local tumor stage and grade as a predictive factor for occult lymph node micrometastasis in patients with penile carcinoma and clinically negative inguinal lymph nodes. JUrol 2001;165(05):1506-1509
28 Chaux A, Caballero C, Soares F, et al. The prognostic index: a useful pathologic guide for prediction of nodal metastases and survival in penile squamous cell carcinoma. Am J Surg Pathol 2009;33(07): 1049-1057

29 Bhagat SK, Gopalakrishnan G, Kekre NS, et al. Factors predicting inguinal node metastasis in squamous cell cancer of penis. World J Urol 2010;28(01):93-98

30 Stewart SB, Leder RA, Inman BA. Imaging tumors of the penis and urethra. Urol Clin North Am 2010;37(03):353-367

31 Ferrándiz-Pulido C, de Torres I, García-Patos V. Carcinoma escamoso de pene. Actas Dermosifiliogr 2012;103(06):478-487

32 Guimarães GC, Cunha IW, Soares FA, et al. Penile squamous cell carcinoma clinicopathological features, nodal metastasis and outcome in 333 cases. JUrol 2009;182(02):528-534, discussion 534

33 Cubilla AL, Reuter V, Velazquez E, Piris A, Saito S, Young RH. Histologic classification of penile carcinoma and its relation to outcome in 61 patients with primary resection. Int J Surg Pathol 2001;9(02):111-120

34 Ficarra V, Akduman B, Bouchot O, Palou J, Tobias-Machado M. Prognostic factors in penile cancer. Urology 2010;76(02, Suppl 1): S66-S73 